\title{
A Study on the Organization and Management of University's Scientific Research Team
}

\author{
Yang Qian \\ The School of Architecture \\ Linyi University \\ Linyi, China \\ e-mail:name@xyz.com
}

\begin{abstract}
The different organizational behavior models of the scientific research team in universities should be suitable to different environments, for in different development stages of the team, there will be different features and environments. Therefore, the organizational behavior models of the team should be on speaking terms with its different development stages. Consequently, we must strengthen the management by objectives in order to create a comfortable and harmonious working atmosphere; we also should reinforce the construction of motivating mechanism and build a team which has an appropriate scale and a harmonious membership structure and a scientific examining and evaluating system; at the same time, we must improve the capabilities of the scientific research in universities so that new achievements can be produced.
\end{abstract}

Keywords-university; scientific research team; organizational behavior models; motivating mechanism management;

\section{INTRODUCTION}

The scientific research personnel in colleges and universities are the backbone of the national scientific and research team, especially in modern society, where the technological collaboration and technical resources sharing have a closer relationship. Every great scientific and technological achievement, so to speak, has been supported by one or more teams. Team has become a basic unit in the scientific research in a university.

The scientific research team in a university, whose object is to research and develop science and technology, mainly consists of scientific research personnel who have the supplementary skill and are ready to be responsible for the common scientific purpose, scientific object, and working procedure. It is one of the scientific research teams of our country, which has its own characteristics besides some basic attributes of the scientific research teams of our country. The scientific research team in universities is the basis of university's educational resources. It takes a university's teaching and scientific research personnel as its mainstay. Therefore, the scientific research can produce a direct or indirect relationship with teaching. Fundamental researches in universities account for a greater proportion, compared with other scientific research teams. Many students in universities especially graduate students have commonly participated in the researches.

\section{THE ORGANIZATIONAL BEHAVIOR MODELS IN UNIVERSITY}

The leader of the team should be highly concerned with the members and task of it and simultaneously must pay close attention to different development stages of team. The above three factors have decided that there will be four kinds of team leaders, namely, directive leaders, persuasive leaders, participatory leaders as well as authorizing leaders. Directive leaders will classify the role of team members and will tell members what to do, how to do, when and where to accomplish different task. Persuasive leaders will supply both direction and support. Participatory leaders rarely order members to do something, but to make a strategic decision together with members. Authorizing leaders will hardly supply direction and support, but to authorize members to complete task autonomously.

The different organizational behavior models of the scientific research team in universities should be suitable to different environments, for in different development stages of the team, there will be different features and environments. Therefore, the organizational behavior models of the team should be on speaking terms with its different development stages. The team, on the basis of maturity, can be divided into four stages, namely, formative period, cohesive period, intensive period, and harvesting period, with the corresponding directive leaders, persuasive leaders, participatory leaders as well as authorizing leaders.

In the formative period of the scientific research team in a university, the team members have different motivations, demands, and characteristics and are short of common aim. They haven not established the relationships so that they cannot trust each other adequately. At the same time, the whole team has not established norms or has not formed the common opinion. At this period, there will be more contradictions but less consistency and a lot of efforts have been done but the effect is not completely obvious. During this time, the team should been controlled strictly and take the directive leadership, namely, the team leader classifies the role and function division of the members. Moreover, the leader will tell the members what to do, how to do, when and where to accomplish different tasks.

In the cohesive period of the scientific research team in a university, the team members will gradually learn the thoughts of the leader and the aim of the team after a lengthy communications. Each other has got tacit 
understanding and has also gradually known the norm of the team. Therefore, the illegal matters are gradually reduced. At this time, persuasive leadership should be adopted, that is, the leader should supply both direction and support. To those people who stick to their guns and cannot be in harmony with the team, the leader should try his best to use persuasive way to help him build common norm of conduct in order to make them blend in the team quickly.

In the intensified period of the scientific research team in a university, the leader should make their efforts to create a free atmosphere and allow team members to put forward different opinions and views, and even encourage the constructive conflicts. The aim will be made on the basis of the common wiliness of members other than the leader's wiliness; the team members will rely on each other instead of mutual suspicion; norms will become an inherent promise rather than an external limit. During this time, the team members will be to be one and be willing to devote their intelligence and originality for the team. In this time, the leader should take a participatory leadership, set him an example to others, and allow different voices to appear. Besides, he should make a common decision together with members.

In the harvesting period of the scientific research team in a university, a strong team has been formed, and all people have a sense of wholeness. At the same time, the team will burst an unprecedented energy and produce a remarkable achievement. Meanwhile, the leader should adopt an authorizing leadership and encourage the subordinate to finish work by an authorizing way simultaneously; the members can strengthen selfleadership and self-mangement through sharing authorities.

\section{THE MANAGEMENT OF THE SCIENTIFIC RESEARCH TEAM IN UNIVERSITIES}

The management of the scientific research team in universities must be reinforced for the sake of improving the scientific research level and innovation ability in universities. However, a long persistent process is needed. The management of the scientific research team in universities should pay much attention to its own longterm development.

\section{A. To enhance team's management by objectives}

The common performance target is the basis of the team, which is the source of team cohesive force and is also the key to success. Successful teams should transform their common aim into a specific, measurable and feasible aim, which should be an important foundation for the team performance evaluation. The target of the scientific research team in universities plays a directive and an improving role in scientific research, which is not only a "steering wheel" of scientific research, but also a motivation that can arouse members' enthusiasm and creative power. This target can improve the team's cohesive force and insure that the whole team moves round the desired goals so that the team doesn't deviate of the direction. It can heighten approval to their roles and team's role through a long-range goal. Thereby, the team members' initiatives and creative desires can be aroused. If the scientific research team carries out management by objectives, scientific efforts will advance smoothly along the correct track and many excellent talents can be supplied constantly. This can form an energetic innovative research team, make the construction of scientific research team become a new impetus and growth points and sequentially push the teaching, science and research, and subject construction to climb up to a new step.

\section{B. To create a comfortable and harmonious working environment}

A comfortable and harmonious working environment can arouse the team member's work ethic and their proficiency can be given to full play, and thus the team can obtain higher performance. Science and research activity is a creative activity which needs enthusiasm and inspiration, especially needs a comfortable and harmonious working environment, for depressive environment will make members lose working initiatives and enthusiasm. A comfortable and harmonious working environment mainly embodies in two aspects: the first one is to form a mutual respecting atmosphere, for people only respect mutual skill, capability, opinion, viewpoint and contribution, better cooperation and efficient work can be brought. The team leader should set him an example to others and communicate with team members amiably and equally in order to arouse members' initiatives and creativity. The other is to utilize a brainstorm frequently because a brainstorm can either satisfy members' participation requirements or concentrate everyone's intelligence. In the brainstorm, different academic views hit against each other, which can expand scientific ideas and enlighten inspiration. Especially in the complicated team, nearly every member comes from different organizations and possesses different professions and skills, so the information is more disperse, and thus the brain storm is more important at this point.

\section{To enhance the construction of team's incentive mechanism}

The team's incentive mechanism can arouse initiatives and enthusiasm of the team and its members, and also can keep team's great vitality and remarkable attraction. It can push the team's work to carry out smoothly, and urge members to study assiduously and to bring their talents into full play so that rich research result can be achieved. Universities should be on the basis of their own characteristics to stick to the priority performance and to intensify the quality of scientific research item and the level of result. Universities should also set up and develop a motivating and operating mechanism which can stir up teacher's enthusiasm and ensure scientific research's sustainable development. At the same time, the team should be given some preferential policies in job subsidies, the workload assessments, professional evaluations, and housing etc. Universities should create a better intellectual atmosphere through incentives, and change the evaluation policies for instant success that the numbers of results are extremely emphasized and is considered as a standard in distributing resource.

\section{To construct a modest scale, member structure complementary team}

A team modest in scale and complementary in member structure usually consists of ten members. If the there are more members, on the one hand, there will be many 
difficulties in communication and hard to reach an agreement; on the other hand, "hitchhike" phenomenon will occur-some members will only make non-labor effort. This phenomenon will cause the cohesive force and loyalty index to be reduced so that mutual trust cannot be achieved. On the base of appropriate personnel amount, if the team wants to carry out the work effectively, the personnel reasonable collocation should be paid more attention. Only to choose appropriate members, the team can produce an active synergistic effect, which will make the performance level of the team be larger than the summation of individual performance. The complementary member structure of the team mainly embodies in the following parts: the first is that the team members have complementary subjects and professional background; the second is that the team members have complementary characters; the third is that the qualifications and age of the team members are reasonably.

\section{E. To construct a scientific team examining and evaluating system}

A set of strict accountability mechanism should be set up in order to reinforce the management of the team construction and ensure that the team construction obtain good results. At the same time, the leader should adopt dynamic management to the team, master coordination principle in time, introduce the competition mechanism, adopt rolling grants to construction, and establish a impeccable management system and smooth operating mechanism in order to make it grow up in a competitive environment to train a high-level science and research team and the team spirit. Meanwhile, the scientific team examining and evaluating system can not only evaluate team at fixed period, but also can promote the team to improve science and research level. Moreover, this system can promote the team to summarize experience and to find gaps so that the team can take improvement measures to reinforce the team construction and management. What' more, assessment norms should be on the basis of subject differences and reflect comprehensive, objective and righteous principle.

\section{CONCLUSION}

The construction of the science and research team in a university has a direct relationship with the improvement of the university's integrated strength and the production of creative science products. Sectors of management of science research should take the best use of the situation, cultivate gradually, stabilize relatively and adjust timely for the sake of reinforcing team's organization and management. However, the team leader should encourage appropriately, authorize properly, integrate intelligently and share knowledge. Based on improving the cohesive force of the science and research team, the team can depend on key discipline and should establish and improving team's interior management, operation, motivation, assessment, and elimination mechanism to become more effective and more highly productive.

\section{REFERENCES}

[1] E. R. Wright, L. A. Russell, J. A. Anderson, et al. "Impact of Team Structure on Achieving Treatment Goals in a Systems of Care," Journal of Emotional and Behavioral Disorders, vol. 14, Winter 2006, pp. 240-250, doi: 10.1177/10634266060140040701.

[2] Huang Jin. "A Study of the Sustainable Development of Scientific Research Team in Universities," Journal of Beijing Institute of Technology (Social Sciences Edition), vol. 11, Oct. 2009, pp. 138141.

[3] G. A. Neuman, J. Wrignt. "Team Effectiveness: Beyond Skills and Cognitive Ability," Journal of Applied Psychology, vol. 84, Jun. 1999, pp. 376-389, doi: 10.1037/0021-9010.84.3.376.

[4] G. L. Stewart, M. R. Barrick. "Team Structure And Performance: Assessing the Mediating Role of Intrateam Process and The Moderating Role of Task Type". Academy of Management Journal, vol. 43, Apr. 2000, pp. 135-148.

[5] R. C. Mayer, J. H. Davis, F. D. Shoorman. "An Integrative Model of Organizational Trust," Academy of Management Review, vol. 20, Jul. 1995, pp. 709-734.

[6] R. M. Mirgab, S. D. Hunt. "Work Organizations as Contexts for Trust and Betrayal," West port, Greenwood Publishing Group, 1994.

[7] B. Barber . "The Logic and Limits of Trust: New Bruns Wick," New Jersey, Rutgers University Press, 1983.

[8] P. M. Doney, J. P. Cannon, M. Rmullen. "Understanding the Influence of National Culture on the Trust," Academy of Management Review, vol. 23, Jul. 1998, pp. 601-620.

[9] D. H. Mackin. "The Team Building Tool Kit-Tips, Tactics, and Rules for Effective Workplace Teams," New York, AMACOM, 1994.

[10] Hank Williams. "The Essence of Managing Groups and Teams,"New Jesrey, Prentice Hall Europe, 1996.

[11] Wang Yiran, Chen Shijun, Zhang Haiyan, et al. "Study on Theoretical Problems in the Construction of Creativity Team in University," Science \& Technology Progress and Policy, vol. 23, Aug. 2007, pp. 194-197.

[12] M. R. Barrick, G. L. Stewart, M. J. Neubert. "Relating Member Ability and Personality to Work- Team Processes and Team Effectiveness," Journal of Applied Psychology, vol. 83, Jun. 1998, pp. 377-391, doi:10.1037/0021-9010.83.3.377.

[13] Barry, G. L. Stewart. "Composition, Process, and Performance In Self-Managed Groups: the Role of Personality," Journal of Applied Psychology, vol. 82, Jan. 1998, pp. 62-78, doi: 10.1037/00219010.82.1.62.

[14] J. R. Hollenbeck, H Moon, A Ellis, et al. "Structural Contingency Theory and Individual Differences: Examination Of External and Internal Person-Team Fit," Journal of Applied Psychology, vol. 87, Jun. 2002, pp. 599-606, doi: 10.1037/0021-9010.87.3.599.

[15] Fang Yong, Wang Ming ming, Liu Mu. "Under Innovation Angle to Discuss Organizational Structure Design of University’s Science and Research Team," Science \& Technology Progress and Policy, vol. 25, May. 2008, pp. 180-183.

[16] H. L. Yang, J. H. Tang. "Team Structure and Team Performance In IS Development: a Social Network Perspective," Information and Management, vol. 41, Jan. 2004, pp. 335-349, doi:10.1016/S0378-7206(03)00078-8 